\title{
Metal-fluoroplastic materials for aviation structural elements
}

\author{
Rogov V.E. \\ Baikal Institute of Natural Management, Siberian Branch of \\ Russian Academy of Sciences \\ Ulan-Ude, Russia \\ rogov54v@mail.ru
}

\author{
Bokhoeva L.A. \\ East Siberia State University of Technology and \\ Management \\ Ulan-Ude, Russia \\ bohoeva@yandex.ru
}

\begin{abstract}
The paper presents the analysis of metalfluoroplastic materials. Russian metal-fluoroplastic materials are not meeting the requirements of regulatory and technical documentation which was adopted by Russian aircraft industry. The review of patents in the area of the methods for obtaining metal-fluoroplastic materials (MFM) was given. Perspectives of development were revealed. These perspectives of development can significantly increase the operational characteristics of metal-fluoroplastic materials. Their use allows increasing the thickness of the work polymer layer tenfold in comparison with traditional materials, and increasing work service and reliability of dry friction components. It is established that the preliminary mechanical treatment of bearing surface of the metal-fluoroplastic material allows ensuring the production of products with high accuracy and working without lubrication for a long time.
\end{abstract}

Keywords - metal-fluoroplastic material, fluoroplastic, bearing, technology, wear resistance

\section{INTRODUCTION}

The class of metal-fluoroplastic bearings and other friction components exists. This class is designed to work without lubrication. The bearings of metal-fluoroplastic materials (MFM) are used in the friction components of the modern aircrafts [1]. In aviation industry these materials are applied in friction components. In fact MFM are light. They have variability in composition and structure, and a wide range of technical properties. For example, we can get a traditional module, where MFM is a tape form. The tape is structural basis of mild steel. A thin layer of copper was applied to the tape. Then a porous layer of spherical particles of tin bronze (diameter of $0.1 \mathrm{~mm}$ and thickness of 0.3-0.4 mm) was applied to the tape. A thin surface layer was formed from a mixture of fluoroplastic with filler (molybdenum disulphide). The layer covers the protruding peaks of the outer spherical bronze particles [2]. MFM have high antifriction properties in the temperature range from 73 to $553 \mathrm{~K} ; \mathrm{pV}=1.5 \mathrm{MPa}-\mathrm{m} / \mathrm{s}$. MFM work well in a vacuum and in liquid media that do not have a lubricating effect. MFM is a replacement for difficult bearings of components. The ultimate wear is concentrated in the surface layer with a thickness of $0.025-0.05 \mathrm{~mm}$. This value affects the durability of the product as a whole [3]. This fact is explained by the insufficient amount of fluoroplastic, because fluoroplastic is in the porous space of bronze particles [4]. In this regard, the material is used mainly in components. The components operate in the modes of hydrodynamic and mixed friction (in friction components: pumps for pumping oil, various rotary mechanisms, hydraulic booster, etc.). MFM in Russia is produced at the machine-building enterprises of the country: (OOO «Composite», OOO «Promsnabkomplekt», Kineshma, OOO «Ftoroplast», Bugulma).

The analysis of the work showed that Russian metalfluoroplastic materials are not fully meeting the requirements of regulatory and technical documentation which was adopted by Russian aircraft industry [1].

Products of material from imported DU and DP grades are widely used in various industries, for example, as guiding sleeves in hydraulic telescopic racks of shock absorbers of all car brands, in gear pumps, in hinges of rear doors GAZ 2705, 33021 "Gazelle", in compressors, in steam turbines, etc.

The increased performance of MFM characteristics of foreign-made is determined by the technology with the use of external pressure during the thermal treatment of the polymer layer in a porous layer [4]. This technology allows fixing the polymer in the pores. The fixation is not achieved with free sintering in air.

It is established that the optimum condition for the operation of sliding bearings is the optimal combination of the amount of polymer and metal in the structures [8]. To significantly increase the operation of MFM characteristics it is necessary to increase the thickness of the polymer working layer. Fixation of fluoroplastic coating - lubrication should be carried out under pressure.

On the basis of this knowledge it is necessary to establish production of these materials with high performance characteristics. These high performance characteristics are not inferior to imported analogues.

\section{LITERATURE REVIEW}

According to the Internet, new enterprises of products MFM and products from it appeared [5-7]. However, the information is of an advertising nature, therefore it is quite difficult to judge the methods of obtaining and the properties of the materials. And the MFM are a fairly wide range of different materials. 
The analysis of existing patents on the methods of obtaining MFM showed a sufficient number of similar developments (the use of explosive treatment in the production of coatings on the cylindrical surfaces of products). But they are not used in practice [9-12].

Increasing the thickness of the polymer layer can be achieved by increasing the pore volume. As porous layers, various matrix materials can use [13]. However, traditional matrix-filled materials are expensive to obtain the required relief on the metal surface of the product [14]. The researchers began using a metal mesh of antifriction materials.

The known method is the preparation of MFM in the form of plates [15-17]. Instead of the traditional porous bronze layer of spherical particles, this method presents the use of various mesh antifriction materials. These antifriction materials are specially kept on the metal surface. The use of antifriction grids can significantly increase the proportion of polymer in the working layer of this material. Therefore, we will dwell in more detail on these technologies. We will give an example of the manufacturing technology of the MFM in the form of plates [18].

\section{MANUFACTURING TECHNOLOGY OF THE METAL- FLUOROPLASTIC MATERIALS}

Fig. 1 presents the algorithm for obtain the MFM in the form of plates.

\begin{tabular}{|c|}
\hline 1. The cutting and processing of steel plates \\
\hline 2. The roasting the mesh material to the base \\
3. The deposition of polymer in a porous layer \\
4. The sintering of fluoroplastic composites in pores \\
\hline
\end{tabular}

Fig. 1. The algorithm for obtain the MFM in the form of plates

Plates of specified sizes from 20 steel are cut. Protective corrosion-resistant coatings on steel are obtained in various ways (for example, by bronzing with diffusion saturation from the coatings). The bronze-brass mesh is cut according to the dimensions of the steel sheets. The package in a special framework is recruited. A gasket of stainless steel 1X18N9T is applied with a thickness of $0.4 \mathrm{~mm}$. A treated plate of 20 steel is applied. Then a bronze-brass mesh and again a stainless steel gasket are applied. The package can contain a large number of plates, depending on the size of the steel frame and the dimensions of the equipment. Then the package is set in square frames. The package is bounded by steel plates with a thickness of $5 \mathrm{~mm}$. Further the package is tightened with wedges. The cassette is placed in a container with activated carbon. The thickness of the coal backfill above the cassette should be at least $2 \mathrm{~cm}$. The container is closed with a lid and a fusible shutter made of crushed glass is guided. The container is placed in an oven heated to $850-880^{\circ} \mathrm{C}$. In an oven the container is held at this temperature for 2 hours. The container is cooled in the air. After cooling, the cassette is removed from the container. Then the cassette is disassembled. In cells meshed with steel plates, a non- orientated film of composite material based on fluoroplastic-4 is pressed under pressure. The technology is prepared as follows. In a high-speed blade 75-80 mass \% of fluoroplast-4 and 20-25 mass \% of lead sulfate are mixed. The obtaining batch is pressed into cylindrical billets at a pressure of 350$500 \mathrm{kgf} / \mathrm{cm}^{2}$. Then the obtaining batch is sintered in an oven at a temperature of $360-380^{\circ} \mathrm{C}$ with a heating time of 0.5 hours per $\mathrm{cm}$ of thickness. A non-orientated film with a thickness of $0.3-0.5 \mathrm{~mm}$ is obtained from the blanks. The film is cut to the size of steel plates. The film is pressed into 2-3 layers at a pressure of $200-300 \mathrm{kgf} / \mathrm{cm}^{2}$. A package of steel plates is collected with the baked bronze-brass mesh and the pressed fluoroplastic film. The bronze-brass mesh and the fluoroplastic film are separated by gaskets of stainless steel or aluminum foil with a thickness of $0.05-0.1 \mathrm{~mm}$. The package is bounded by thick stainless steel plates and framed. It is fixed of wedges. The collected cassette is placed in a container with a carbon backfill. The container is closed with a lid and sealed. It is heated in an oven to a temperature of $370-380^{\circ} \mathrm{C}$ at a rate of $100^{\circ} \mathrm{C} / \mathrm{h}$ within $1-2$ hours at this temperature. Cooling is carried out with the oven. After cooling, the cassette is removed from the container and disassembled. When the polymer film is pressed into the free space of the mesh continuity is violated. The process of monolithization of the polymer is possible only when the plate blanks are sintered in a limited volume. In the closed space, pressure is created due to the thermal expansion of the fluoroplastic. Finished details from the obtained fluoroplastic blanks are manufactured by stamping and calibration.

Due to the use of different numbers and types of web fabrics, this method allows one to obtain the MFM with a wide range of physic-mechanical and tribo-technical characteristics. The obtained materials present composite antifriction materials with a heterogeneous structure. The heterogeneous structure is consisted of regularly alternating sections of a bronze mesh with a relatively low friction coefficient and a polymer. The friction is able to form an intermediate pre-setting layer with a uniform distribution of the polymer over the entire thickness of the mesh. The material has high wear-resistant properties. The material operates over a wide range of temperatures and loads under conditions of dry friction at $\mathrm{pV}>3 \mathrm{MPa}-\mathrm{m} / \mathrm{s}$ [19]. The friction process proceeds with the constant presence of fluoroplastic-4 up to the value of the maximum permissible wear of triboconjugation as a whole. However, such materials are not widely used, according to the authors, because the contour and actual areas of the metal contact are changed in the materials [4]. This fact does not allow you to accurately calculate the load on finished products. The main load in such a node is distributed on a solid surface. At the initial moment of contact between the metal counter and the mesh, contact occurred only along the vertices of the wefts.

Fig. 2 presents a fragment of the cross section of such a material. This material consists of a metal mesh material (one weft woven around the warp threads). The metal mesh material is fixed with a metal plate. It is filled with a polymer composite. 


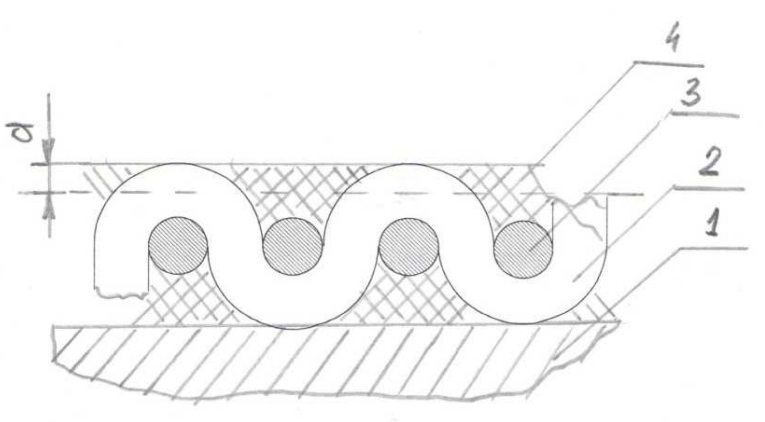

Fig. 2. The fragment of MFM section: 1 - the metal plate; $2-$ the base of mesh material; 3 - the weft of mesh material; 4 the composite on the basis of polytetrafluorethylene

\section{DISCUSSION}

The calculation of the change in the contact area as a function of the amount of linear wear is theoretically calculated in [20]. The increase in the contour and actual contact area of the bearing element occurs as the bronze mesh wears off. In this regard, in the initial period of operation, large loads arise at the points of contact of the shaft with the mesh material. The magnitude of the loads can be higher than the maximum allowable specific pressure. This leads to considerable wear. It is established that the maximum contour contact area for net weft is achieved with linear wear. Linear wear is approximately $2 / 3$ of the diameter of the weft wire. The sliding bearing is reached the maximum permissible wear between the bearing shell and the shaft. It turns out that the sliding bearing has specific loads much lower than at the beginning of exploitation. However, due to significant wear, it is rejected. Thus, to increase the longevity of such components, measures are needed to reduce this dependence. Experiments on the use of grids of another weave show that such paths cannot completely solve this problem. For example, experiments are of the twill and the reduction of wire diameters in a smaller direction. The mechanical treatment of the work heterogeneous surface of the bearing shell assembly is led to the formation of a metal surface without a polymer layer. The absence of an antifriction layer can lead to the setting of metal surfaces. The most promising option is the preliminary mechanical treatment of the mesh surface of the material in size. Mechanical treatment should be carrying out after the diffusion bonding of the mesh material to the metal substrate. This process allows obtaining the output accuracy of the final dimensions of the material, taking into account the permissible deviations of steel sheets in thickness. It is established that the optimal value of the contour area of the mesh is achieved after machining to a depth of 0.5 diameter of the weft wire. Fig. 2 presents the dashed line layer, which must be removed by mechanical treatment.

\section{CONCLUSION}

Russian traditional technologies of manufacture of the MFM do not yet allow obtaining materials with high exploitation properties due to the insufficiency of the polymer lubricant in the pores of bronze. Currently, a large number of patents on the methods of obtaining of the MFM are existed. The developments fix and significantly increase the layer of the antifriction polymer. These developments are perspective. As a porous layer, antifriction mesh materials are used. These technologies are perspective methods. The use of technologies allows increasing the thickness of the polymer working layer by a factor of ten compared to traditional materials, the resource of work and the reliability of dry-friction components. It is established that the preliminary mechanical treatment of bearing surface of the metal-fluoroplastic material allows ensuring the production of products with high accuracy and working without lubrication, for a long time.

The research was supported by the Ministry of Education and Science of the Russian Federation, project №9.7667.2017/БЧ, project №9.11221.2018/11.12.

\section{REFERENCES}

[1] C.A. Bychkov, I.G. Lavrenko, O.Yu. Nechiporenko, I.M. Romashko, S.D. Mladinov, "Research of characteristics of metal-fluoroplastic of various manufacturers for elements of aviation constructions", J. Open information and computer integrated technologies, №59, pp. 343-354, 2013.

[2] V.S. Lagunov and etc., "Manufacture of products made of metal-fluoroplastic composite materials", J. Mashinostroenie, №4, pp. 16-18, 1996.

[3] Yu.K. Mashkov, Z.N. Ovchar, M.Yu. Baibaratskaya, O.A. Mamaev, Polymer composites in tribotechnics, Russia: OOO “Nedra-Business Center”, p. 262, 2004.

[4] V.E. Rogov, A.M. Guryev, S.O. Nikiforov, E.A. Kosheleva, "Metal-fluoroplastic materials for power engineering: specific features, development, production, application, development trend", J. Polzunovsky Herald, №1, pp.134-140, 2010.

[5] http://promglex.ruln.ru

[6] http://www.pskomplekt.narod.ru

[7] http://www.triolent.ru

[8] V.A. Belov, Metal-polymer materials and products, Russia: Chemistry, p. 312, 1979.

[9] Patent RF 2286231. Multilayer metal-fluoroplastic tape and a way of it is manufacturing. Kalinichenko V.G., Kovalenko D.V., Chugunov V.F., Shcheglov E.L. (In Russian).

[10] Patent RF 2186658. Method for manufacturing fluoroplastic tape. Komarov S.S., Belyaev B.A., Khatmullin V.R., Nabiullin V.Kh., Baibulatov V.P. (In Russian).

[11] Patent RF 2033922. Method for obtaining metallfluoroplastic coatings from a powdery material on the cylindrical surface of articles. Adamenko N.A., Trykov Yu.P., Fetisov A.V., Gurevich L.M., Kazurov A.V. (In Russian).

[12] Patent RF 2210462. Method of manufacturing multilayer metal-fluoroplastic tape. Kalinichenko V.G., Kovalenko D.V., Chugunov V.F., Shcheglov E.L. (In Russian).

[13] A.S. Chermoshentseva, A.M. Pokrovskiy and L.A. Bokhoeva, "The behavior of delaminations in composite materials - experimental results", IOP Conference Series: Materials Science and Engineering, URL: http://iopscience.iop.org/article/10.1088/1757$\underline{899 X / 116 / 1 / 012005 / p d f}, 2015$ [International Conference 
on Advanced Materials and New Technologies in Modern Materials Science, 2016].

[14] V.A. Bely, A.I. Sviredenok, M.I. Petrakovich and etc., Friction and wear of materials based on polymers, Minsk: Science and Technology, p. 430, 1976.

[15] Patent RF 1398244, 1992. Method of manufacturing multilayer antifriction products. Kornopoltsev N.V. (In Russian).

[16] Patent RF 1418999. Method for obtaining bimetallic metal-fluoroplastic material. Kornopoltsev N.V. Published 1993. (In Russian).

[17] Patent RF 1418999. Method for producing bimetallic metal-fluoroplastic material. Kornopoltsev N.V. Published 1995. (In Russian).

[18] Patent RF 2212307. Method for the production of bimetallic metal-fluoroplastic material. Kornopoltsev V.N., Kornopoltsev N.V., Rogov V.E., Mognonov D.M., Greshilov A.D. Published 17.01.2002.

[19] V.N. Kornopoltsev, N.V. Kornopoltsev, D.M. Mognon, "Tests of metal-fluoroplastic sheet antifriction materials at slip speeds up to $3 \mathrm{~m} / \mathrm{s}$ ", J. Friction and wear, vol. 30, №4, pp. 1-5.

[20] V.E. Rogov, B.E. Marhadaev, "Dynamics of abrasion of metal-polymer materials in the process of operation", J. Friction and lubrication in machines and mechanisms, №7, pp.33-37, 2010. 